\section{Strategies for preventing}

\section{calcium oxalate stones}

A bout 10\% of people will experience nephrolithiasis in their lifetime, and about $70 \%$ of those will have recurrences. About $80 \%$ of stones are calcium based, and about $80 \%$ of those are calcium oxalate stones. We discuss here briefly the evidence for the prevention of calcium oxalate stones through dietary and pharmacologic measures.

\section{Urinary risk factors}

Both genetic and environmental factors contribute to stone formation, but the genes responsible for the heritable aspect of stone formation have not been delineated definitively. Mainstays of calcium stone prevention involve manipulation of urine chemistries (urine sodium, citrate, oxalate, uric acid and calcium levels as well as urine specific gravity). The urinary risk factors most often implicated in stone formation are listed in Table I. Hypercalciuria is the most common trait associated with cal- cium stones, yet its cause in most patients remains unclear. It is still often referred to as "idiopathic hypercalciuria." The efficacy of classifying hypercalciuria on the basis of cause remains controversial and of unproven value in clinical management.

\section{Dietary modification}

\section{Fluid intake}

The cornerstone of management is to increase urine volume. The effect appears to be linear, with a point of diminishing return reached at urine volumes of more than 2.5 L per day. We prescribe an intake of $2.5^{-3} \mathrm{~L}$ of fluids per day.

There are data to suggest that the type of fluid ingested matters. Epidemiologic studies show that drinking coffee and beer decreases the risk of stones. Drinking grapefruit juice consistently increases stone risk for unclear reasons, whereas lemon juice, higher in citrate content, might have beneficial effects on urinary chemistry but its ingestion has not been shown to prevent stones.

\section{Calcium}

Studies of dietary calcium's effect on stone recurrence rates have led to major changes in nonpharmacologic manipulation. Epidemiologic evidence shows an inverse relation between dietary calcium intake and recurrence rates. This is probably best explained by calcium's inhibition of intestinal oxalate absorption. A randomized controlled trial (RCT) assigned men with hypercalciuria to follow either a diet low in calcium (400 mg) and oxalate or a diet higher in calcium (I200 $\mathrm{mg}$ ) with restricted intake of oxalate, protein and salt. ${ }^{1}$ At 5 years, the latter group had a $5 \mathrm{I} \%$ lower rate of stone recurrence than those following a low-calcium diet. Although controversy persists and replication of these findings under other clinical circumstances would be desirable, low-calcium diets are not recommended and can exacerbate the well-documented association of hypercalciuria with low bone mineral density and increased fracture rates. ${ }^{2}$ Whether calcium supplements could have a similar effect in lowering stone recurrence rates has not been tested. Taking cal-

Table 1: Urinary risk factors for calcium stone formation

\begin{tabular}{|c|c|c|c|}
\hline Risk factor & Causes & Treatment & Level of evidence \\
\hline Low urine volume & $\begin{array}{l}\text { Exercise, sweating, low fluid } \\
\text { intake, heat, bowel disease }\end{array}$ & Increase fluid intake to $2.5-3.0 \mathrm{~L} / \mathrm{d}$ & $\begin{array}{l}\text { RCT (Borghi et al. J Urol } \\
1996 ; 155: 839-43 \text { ) }\end{array}$ \\
\hline Hyperoxaluria & $\begin{array}{l}\text { Dietary ingestion and endogenous } \\
\text { metabolism; inflammatory bowel } \\
\text { disease }\end{array}$ & $\begin{array}{l}\text { Restrict oxalate intake; increase } \\
\text { dairy intake accompanying oxalate- } \\
\text { containing foods }\end{array}$ & $\begin{array}{l}\text { No RCT (Holmes et al. Urol Res } \\
\text { 2004;32:311-6) }\end{array}$ \\
\hline Hypocitraturia & $\begin{array}{l}\text { Renal tubular acidosis; other } \\
\text { metabolic acidoses; chronic bowel } \\
\text { disease; often idiopathic }\end{array}$ & $\begin{array}{l}\text { Begin potassium citrate } \\
\text { supplementation }\end{array}$ & $\begin{array}{l}\text { RCT (Barcelo et al. J Urol } \\
\text { 1993;150:1761-4) }\end{array}$ \\
\hline
\end{tabular}

Note: $\mathrm{RCT}=$ randomized controlled trial . 
Box 1: Foods most commonly responsible for raising urine oxalate levels

- Rhubarb

- Dark green leafy vegetables (e.g., spinach, chard, arugula)

- Beets

- Wheat bran

- Nuts, seeds

- Soy products

- Chocolate

- Tea

- Strawberries

Source: Massey L et al. J Am Diet Assoc 1993;93: 901-6. See also www.ohf.org/docs/Oxalate2004.pdf and www.litholink.com/patientsDietInfo.htm

cium carbonate supplements with meals reduces oxaluria, whereas taking them at bedtime increases calciuria and has no effect on oxaluria. ${ }^{3}$ The preferred calcium supplement for people at risk of stone formation is calcium citrate because it helps to increase urinary citrate excretion. We recommend a dose of $200-400 \mathrm{mg}$ if dietary calcium cannot be increased.

\section{Oxalate}

The intake of foods high in oxalate should be limited. Although there are many such foods, some more frequently than others have been shown to be most at fault for raising urine oxalate levels (Box I). Their impact might be mitigated by accompanying them with additional fluids and dietary sources of calcium to diminish oxalate absorption. No pharmacologic intervention has definitively been shown to be effective. Of note, since vitamin $\mathrm{C}$ can convert to oxalate, the use of vitamin C supplements may increase oxaluria and be associated with an increased risk of stone formation; therefore, the dose of these supplements should be limited to less than Iooo $\mathrm{mg} / \mathrm{d}$.

\section{Sodium}

Calcium excretion is directly linked to sodium excretion. Reductions in dietary sodium reduce calciuria, but no RCT of sodium restriction alone has been performed. The successful diet mentioned earlier that was higher in calcium and restricted intake of oxalate, protein and salt ${ }^{1}$ achieved a reduction in calcium excretion despite the higher calcium intake. This effect was attributed to the reduction in dietary sodium intake to less than $2 \mathrm{~g} / \mathrm{d}$.

\section{Protein}

The ingestion of animal protein has adverse affects on urine chemistries: it lowers citrate excretion and increases calcium and uric acid excretion. Epidemiologic data show that it correlates well with the prevalence of stone formation. The recent popularity of diets low in carbohydrates and high in animal protein have refocused attention on protein intake as a risk factor for stones. ${ }^{4}$ Patients with recurrent stones should minimize their protein intake to less than $80 \mathrm{~g} / \mathrm{d}$.

\section{Role of diabetes and obesity in stone formation}

Recent data have suggested an increased prevalence of stones among people with diabetes and among obese people. Insulin resistance may reduce urinary citrate excretion and increase calcium excretion, and a greater body mass index is associated with increases in urinary oxalate excretion. Low urine $\mathrm{pH}$ is associated with increased risk of uric acid stones as well. Weight loss (through a mechanism other than a diet high in animal protein) and improved diabetes control may help to prevent stone formation in appropriate patients, although this approach has yet to be tested in an RCT.

\section{Drug therapy}

\section{Thiazide diuretics}

Thiazide diuretics (e.g., hydrochlorothiazide, chlorthalidone and indapamide) have been proven in RCTs to be effective in reducing calciuria and stone recurrence. These drugs also induce positive calcium balance and thereby increase bone mineral density. Sodium restriction must be employed, and hypokalemia must be avoided since it can lead to hypocitraturia. The usual starting dose is $\mathbf{2} 2.5^{-25} \mathrm{mg}$ of chlorthalidone or hydrochlorothiazide. Most patients should receive supplementation with potassium citrate. Amiloride may help avoid hypokalemia, but triamterene should be avoided because of its low solubility.

\section{Alkalinizing agents}

Citrate inhibits the formation and growth of calcium crystals. Its use has been advocated both in patients with low urinary citrate excretion and in patients who have had calcium oxalate stones but who do not have this urinary abnormality. Use of the potassium salt is preferred, since sodium citrate supplementation will lead to increased calciuria.

\section{Allopurinol}

A minority of patients with calcium oxalate stones have hyperuricosuria as their only identifiable metabolic risk factor. Uric acid facilitates the precipitation of calcium oxalate crystals. A single RCT demonstrated the efficacy of allopurinol, roo mg 3 times daily (although we prescribe $300 \mathrm{mg}$ once daily), to reduce calcium stone formation. ${ }^{5}$ No benefit of allopurinol in patients with hypercalciuria was identified.

\section{Fish oil}

Interest in fish oil supplementation arose from the observation that kidney stones were virtually absent in the Inuits of Greenland, a population with a dietary mainstay of fresh fish. Supplementation with eicosapentaenoic acid leads to reduced calciuria but has not been tested in an RCT.

\section{Summary}

A limited number of RCTs have shown that a good strategy for preventing the recurrence of calcium oxalate stones includes increasing fluid intake, increasing the dietary intake of calcium and restricting the intake of salt, animal protein and oxalate-rich foods. Treatment with a thiazide diuretic, allopurinol and citrate has a role in se- 
lected cases. Several other means of manipulating urinary chemistries have not been adequately tested in RCTs directed at stone prevention.

\section{Vadim A. Finkielstein}

Princeton Hypertension Nephrology Associates

University of Medicine and Dentistry of New Jersey

Piscattaway, NJ

David S. Goldfarb

Nephrology Section
New York Harbor VA Medical Center Department of Urology

St. Vincent's Hospital and NYU School of Medicine New York, NY

This article has been peer reviewed.

Competing interests: None declared.

\section{REFERENCES}

I. Borghi L, Schianchi T, Mecschi T, et al. Comparison of two diets for the prevention of recurrent stones in idiopathic hypercalciuria. $N$ Engl J Med 2002;346:77-84

2. Lauderdale DS, Thisted RA, Wen $\mathrm{M}$, et al. Bone mineral density and fracture among prevalent kidney stone cases in the Third National Health and Nutrition Examination Survey. J Bone Miner Res 200I;16:I893-8.

3. Domrongkitchaiporn S, Sopassathit W, Stitchantrakul W, et al. Schedule of taking calcium supplement and the risk of nephrolithiasis. Kidney Int 2004;65:I835-4I.

4. Reddy ST, Wang CY, Sakhaee K, et al. Effect of low-carbohydrate high-protein diets on acid-base balance, stone-forming propensity, and calcium metabolism. Am J Kidney Dis 2002;40:265-74

5. Ettinger B, Tang A, Citron JT, et al. Randomized trial of allopurinol in the prevention of calcium oxalate calculi. $N$ Engl J Med I986;315:1386-9.

\section{The complete} picture on research.

\section{PRACTICAL. RELEVANT. CMAJ IS NOW} MORE COMPREHENSIVE THAN EVER.

CMAJ's reputation and wide Canadian and international reach make it THE place to publish leading Canadian research. CMAJ publishes important peer-reviewed research within weeks of submission and ranks fifth among international general medical journals by impact factor, a measure of the scientific importance of a journal.

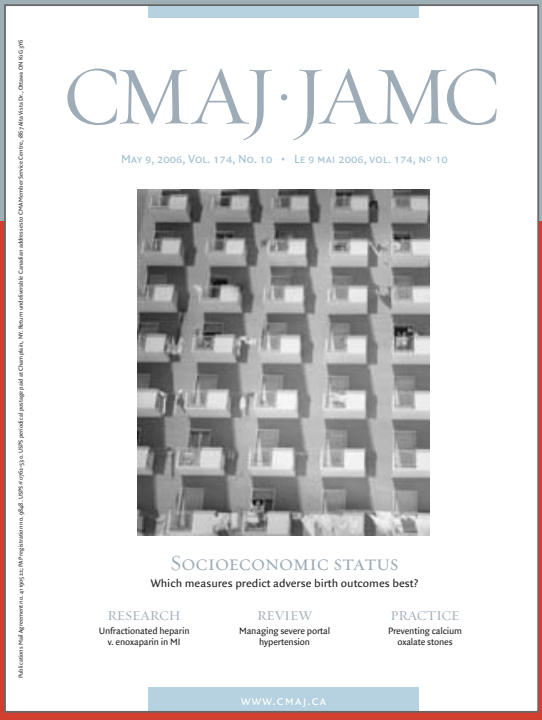

The essential read. ${ }^{\mathrm{TM}}$ 